\title{
Analytic examination of mechanism for compressive residual stress introduction with low plastic strain using peening
}

\author{
Ryo ISHIBASHI*, Hisamitsu HATO*, Fujio YOSHIKUBO** and Katsumasa MIYAZAKI* \\ ${ }^{*}$ Center for Technology Innovation - Materials, Research \& Development Group, Hitachi, Ltd. \\ 7-1-1, Omika-cho Hitachi-shi, Ibaraki 319-1292, Japan \\ E-mail: ryo.ishibashi.wt@hitachi.com \\ **Hitachi-GE Nuclear Energy, Ltd.
}

5-2-2, Omika-cho Hitachi-shi, Ibaraki 319-1221, Japan

Received 10 May 2016

\begin{abstract}
Our goal for this study was to understand the cause of the differences in surface properties between surfaces processed using water jet peening (WJP) and shot peening (SP) and to examine the compressive residual stress introduction process with low plastic strain using SP. The dynamic behaviors of stress and strain in surfaces during these processes were analyzed through elasto-plastic calculations using a finite-element method program, and the calculated results were compared with measured results obtained through experiments. Media impacting a surface results in a difference in the hardness and microstructure of the processed surface. During SP, a shot deforms the surface locally with stress concentration in the early stages of the impact, while shock waves deform the surface evenly throughout the wave passage across the surface during WJP. A shot with a larger diameter creates a larger impact area on the surface during shot impact. Thus, SP with a large-diameter shot suppresses the stress concentration under the same kinetic energy condition. As the shot diameter increases, the equivalent plastic strain decreases. On the other hand, the shot is subject to size restriction since the calculated results indicate the compressive residual stress at the surface decreased and occasionally became almost zero as the shot diameter increased. Thus, compressive residual stress introduction with low plastic strain by using SP is considered achievable by using shots with a large diameter and choosing the appropriate peening conditions.
\end{abstract}

Key words : Shot peening, Water jet peening, Hardening, Plastic strain, Residual stress, Austenitic stainless steel, Elasto-plastic calculations

\section{Introduction}

Water jet peening (WJP) has been applied in several nuclear power plants in Japan for preventing stress corrosion cracking (SCC). Hardening of materials is thought to be a factor in SCC initiation (Kuniya, et al., 2007, and Takeda, et al., 2008). The WJP process introduces compressive residual stress reaching hundreds of micrometers in depth (Saitou, et al., 2003), comparable with shot peening (SP), but much smaller plastic deformation at the processed surfaces. A surface processed using WJP showed a hardness increase of $70 \mathrm{HV}$, while a surface processed using SP showed a hardness increase of $250 \mathrm{HV}$ and a severely deformed microstructure (Kaneda et al., 2009). The SP compressive residual stress creation mechanism, in which hard shots directly impact the surface, has been clarified through experiments and elasto-plastic calculations using a finite-element method program (Ogawa et al., 1999, and Konishi, et al., 2000). On the other hand, the WJP mechanism, in which shock waves induced by cavitation extinctions impact the surface, was suggested through experiments and elasto-plastic calculations using a finite-element method program (Ishibashi et al., 2010). The mechanism of underwater laser irradiation, which also induces shock waves, was suggested by analyzing the propagation of a shock wave and the dynamic response of the irradiated material through elasto-plastic calculations using a finite-element method program (Sano, et al., 2000). The objective for this study was to understand the cause of the differences in surface properties between surfaces processed using WJP and SP and to examine the compressive residual stress introduction process with low plastic strain using SP. We analyzed the dynamic 
behaviors of stress and strain in the surface during these processes through elasto-plastic calculations using a finite-element method program and compared the calculated results with measured results obtained through experiments.

\section{Experimental procedure}

\subsection{Materials and Peening}

We evaluated 316L stainless steel used as an internal core structure material in nuclear reactors for this study. The chemical composition and tensile properties of this steel used for evaluation of residual stress at surface portions using peening processes are listed in Table 1 . The steel was solution-heat-treated at 1332-1342 K for 1.84 ks followed by water quench. It was also annealed at $1143 \mathrm{~K}$ for $7.2 \mathrm{ks}$ followed by air cooling for strain release.

Electro-polished surfaces of plate specimens (200 mm in length, $200 \mathrm{~mm}$ in width, and $20 \mathrm{~mm}$ in thickness) of the steel were processed with either WJP or SP. The WJP specimens were processed at a water flow rate of $8 \times 10^{-4} \mathrm{~m}^{3} / \mathrm{s}$ for an accumulative process time of $2400 \mathrm{~s} / \mathrm{m}$. The SP specimens were processed by shooting 304 stainless steel shots 0.4 $\mathrm{mm}$ in diameter at an injection rate of $0.058 \mathrm{~kg} / \mathrm{s}$ using an air pressure of $0.5 \mathrm{MPa}$ from a nozzle $190 \mathrm{~mm}$ distant traveling at a speed of $6.7 \times 10^{-3} \mathrm{~m} / \mathrm{s}$ parallel to the surface of the plate specimens. The shots were fabricated using heavily cold working processes and exhibited hardness of $625 \pm 20 \mathrm{HV}$ at a test load of $1.96 \mathrm{~N}$. The peening nozzle traveled along the center line of the plate specimens. Thus, the area treated by peening exhibited zonal distribution. The effect of peening gradually decreased as the distance from the center line. The average diameter of observed impact scars was $0.25 \mathrm{~mm}$ for WJP and $0.12 \mathrm{~mm}$ for SP. The scars considerably overlapped around the center line.

Table 1 Chemical composition and tensile properties of 316L stainless steel used.

\begin{tabular}{|c|c|c|c|c|c|c|c|c|c|c|c|}
\hline \multicolumn{9}{|c|}{ Chemical composition (mass.\%) } & \multirow{2}{*}{$\begin{array}{c}\sigma_{0.2} \\
(\mathrm{MPa})\end{array}$} & \multirow{2}{*}{$\begin{array}{c}\sigma_{\mathrm{B}} \\
(\mathrm{MPa})\end{array}$} & \multirow{2}{*}{$\begin{array}{l}\text { EL } \\
(\%)\end{array}$} \\
\hline $\mathrm{C}$ & $\mathrm{Si}$ & $\mathrm{Mn}$ & $\mathrm{P}$ & $\mathrm{S}$ & $\mathrm{Cr}$ & $\mathrm{Ni}$ & Mo & $\mathrm{Fe}$ & & & \\
\hline 0.009 & 0.73 & 1.26 & 0.022 & 0.001 & 17.69 & 12.13 & 2.09 & Bal. & 260 & 585 & 61 \\
\hline
\end{tabular}

\subsection{Residual stress and strain measurement}

We used the $\sin ^{2} \psi$ method to determine the residual stresses at the surfaces for a diffraction peak from the $\{311\}$ plane using a V-Ko characteristic X-ray. Residual stresses were measured after predetermined thicknesses were removed from the surface by electro-polishing to obtain their depth profile.

Cross-sectional hardness and misorientation in the grain were used to estimate the plastic strain in the deformed portions. The cross-sectional hardness was measured using test forces of 0.049 and $9.8 \mathrm{~N}$. The cross-sectional surfaces for the hardness measurement were finished by polishing with an abrasive of colloidal silica.

The relationship of cross-sectional hardness with a plastic strain processed by tensile deformation (Ishibashi et al., 2010) and cold rolling (Kuniya et al., 2007) is shown in Fig. 2. The hardness increased as plastic strain increased. The hardness measured at a test force of $0.049 \mathrm{~N}$ was higher than that at a test force of $9.8 \mathrm{~N}$ for specimens with smaller plastic strains, while they were the same for specimens with larger plastic strains. The differences in hardness for specimens with smaller plastic strains can likely be attributed to the deformation of the remaining surface layer during specimen preparation and inherent test force dependency. Hardness does not depend on indentation depth for inherently harder materials; however, it increases as the indentation depth decreases for softer materials with higher work hardening rates (Nix, 1997, and McElhaney et al., 1998). Thus, the hardness measured at a test force of $9.8 \mathrm{~N}$ is considered the same hardness at a test force of $0.049 \mathrm{~N}$ in the region of a plastic strain of more than 0.3 , as shown in Fig. 2. A correlation curve calculated using Eq. (1) was determined from the hardness data at a test force of $0.049 \mathrm{~N}$ in the region of a plastic strain of less than 0.3 and at a test force of $9.8 \mathrm{~N}$ in the region of a plastic strain of more than 0.3 .

$$
H V=-160 \varepsilon_{p}^{2}+332 \varepsilon_{p}+172
$$

Electron backscatter diffraction (EBSD) patterns were measured using the orientation imaging microscopy $\left(\mathrm{OIM}^{\mathrm{TM}}\right)$ system of TexSEM laboratories. The grain reference orientation deviation (GROD) was used as a measure of misorientation in the grain and is defined as the orientation deviation from the point in the grain with the lowest kernel 
average misorientation (KAM). The KAM for a given point is defined as the average misorientation between the point and its neighbors. Misorientation in the grain increases linearly as plastic strain increases up to about 0.2 for austenitic stainless steels (Angeliu, 1999, Kimura, 2005, and Kamaya, 2006). Although the spacing between the measured points affects the KAM, it affects the GROD only slightly if it is small enough compared with the grain sizes. The GROD

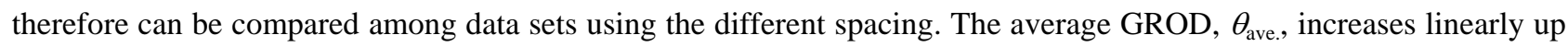
to the plastic strain, $\varepsilon_{\mathrm{p}}$, of 0.2 with the relationship provided from Eq. (2) (Ishibashi et al., 2010).

$$
\theta_{\text {ave. }}=31.5 \varepsilon_{p}+0.347
$$

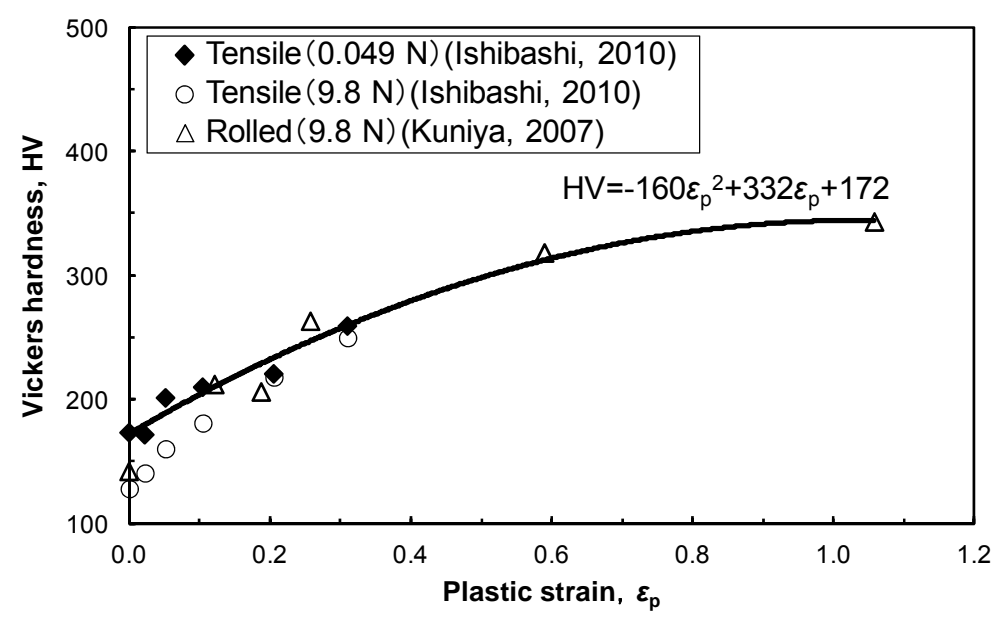

Fig. 1 Cross-sectional Vickers hardness of 316L stainless steel with various plastic strains.

\section{Theoretical analysis}

We conducted a pulse-load propagation simulation through elasto-plastic calculations using a finite-element method program, LS-DYNA, to analyze the effects of various parameters of the impact processes on the depth profiles of the residual stress and amount of plastic deformation on the surface of austenitic stainless steels processed with either WJP or SP. The two-dimensional axisymmetrical mesh configurations used for the analysis are shown in Fig. 2. A shock wave from cavitation bubble collapse spherically propagates in water and impacts surface (Fujikawa, 1984). The impact of a shock wave with WJP is expressed as a spatially homogeneous pulse-load on a circular area on the surface for simplicity. The size of loaded circular area remains unchanged during the impact. The pulse-load is a triangle wave with a maximum loaded force of $2 \mathrm{GPa}$, as shown in Fig. 2. On the other hand, the impact of an SP shot is expressed as a pulse-load of the impact of a hard sphere on the surface. For simplicity, the hard sphere is treated as rigid body because the 304 stainless steel shots exhibit high hardness. Both the loaded force and loaded area vary during impact for deformation of the surface.

The elasto-plastic parameters of the austenitic stainless steels used for the calculation are listed in Table 2. According to these analyses, the average equivalent strain rate at surface during impact is from $10^{3}$ to $10^{5} \mathrm{~s}^{-1}$. Although strain-rate dependency of mechanical properties for steels, including austenitic stainless steel, is well known, data of mechanical properties at strain rate higher than $1 \times 10^{3} \mathrm{~s}^{-1}$ are not sufficient. The yield stress of 304 stainless steel increases from approximately $300 \mathrm{MPa}$ at a strain rate of $1.3 \times 10^{-3} \mathrm{~s}^{-1}$ to approximately $390 \mathrm{MPa}$ at a strain rate of $2.0 \times 10^{1} \mathrm{~s}^{-1}$ (Hirayama, 1984). The yield stress of carbon steels increases from approximately $320 \mathrm{MPa}$ at a strain rate of $1 \times 10^{-1} \mathrm{~s}^{-1}$ to approximately $540 \mathrm{MPa}$ at a strain rate of $5.0 \times 10^{3} \mathrm{~s}^{-1}(\mathrm{Nebu}, 2015)$. The yield stress of approximately 600 MPa is extrapolated at strain rates of $10^{4}$ to $10^{5} \mathrm{~s}^{-1}$ from these tendencies. Thus, the dynamic yield stress for a surface without work-hardening assumed to be $600 \mathrm{MPa}$. On the other hand, dynamic yield stress for a surface work-hardened by SP is assumed to be $1300 \mathrm{MPa}$. The simulation was conducted assuming that the surfaces were homogenous or homogenously deformed using previous peening. 
The area loaded by WJP is circular where a spatially homogeneous pulse-load impacts the surface. On the other hand, the area loaded by SP is the maximum area coming into contact with a shot. This area varied during impact and depended on the size and velocity of the shot. The loaded area size in the analyses was applied based on the size of the impact scars. The loaded cycle in the analyses was under condition of three impacts at the same point on the surface.

The parameters of the elasto-plastic calculation for WJP are listed in Table 3. The parameters of the pulse-load were based on the cavitation bubble collapse phenomena. Some researchers have reported that the bubble collapse pressure is 1 to $10 \mathrm{GPa}$ from theoretical and experimental methods, and the collapse period is 2 to $3 \mu$ s (Okada, 1998). The diameters of the loaded area were based on observation results of the surface processed using WJP. The diameters of the impact scars on the processed surface were 0.04 to $0.95 \mathrm{~mm}$, and the average diameter of the impact scars was $0.25 \mathrm{~mm}$. The loaded area size in the analyses was applied based on the size of the impact scars. The effects of the loaded force and loaded area size during impact on the depth profiles of residual stress and amount of plastic deformation are described in a previous paper (Ishibashi, et al., 2010).

The parameters of the elasto-plastic calculation for SP conformed to the experimental condition. The velocity of a hard sphere with a diameter of $0.4 \mathrm{~mm}$ injected using an air pressure of $0.5 \mathrm{MPa}$ was determined to be $75 \mathrm{~m} / \mathrm{s}$ based on the reported relationship between the diameter and velocity by various air pressures (Ogawa, 1994). The four conditions in Table 3 were determined to investigate the effect of shot diameter on the depth profiles of the residual stresses and amount of plastic deformation under the same kinetic energy condition of $7.5 \times 10^{-4} \mathrm{~J}$ for a density, $\rho$, of $8.0 \times 10^{3} \mathrm{~kg} / \mathrm{m}^{3}$.

The removal of the surface layer causes the redistribution of stress and strain from the residual stress and strain distributions after peening. To compare the calculated results with the experimental results, the redistribution of stress and strain was calculated after removing two meshes $25 \mu \mathrm{m}$ in depth and $50 \mu \mathrm{m}$ in radius in the depth direction. The removed area was small enough to be involved in a compressive residual stress area similar to the experimental condition.

The loaded area diameter of $0.25 \mathrm{~mm}$ by WJP in the analysis was applied based on the average size of the observed impact scars with diameters from 0.04 to $0.95 \mathrm{~mm}$. The loaded area diameter of approximately $0.2 \mathrm{~mm}$ during impacts of SP (shot diameter: $0.4 \mathrm{~mm}$ ) was derived from this analyses and close to the observed impact scars with diameters of 0.1 to $0.2 \mathrm{~mm}$. Thus, the loaded areas applied in the analyses are considered reasonable and appropriate as representative values.

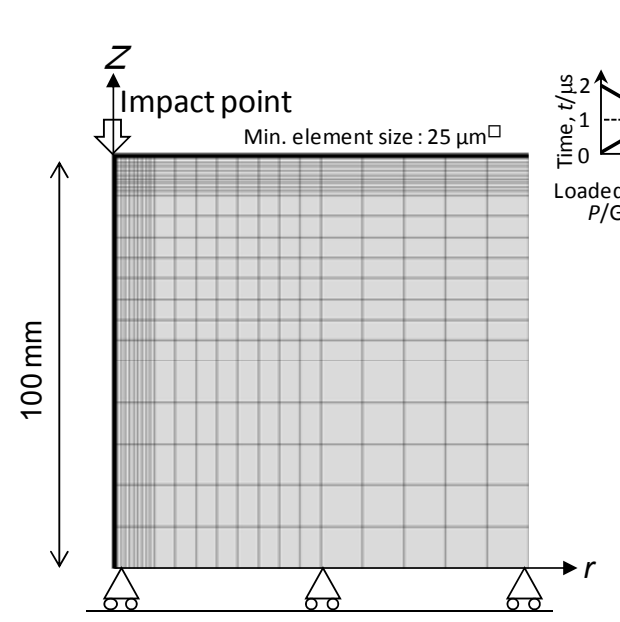

(a) Mesh configuration

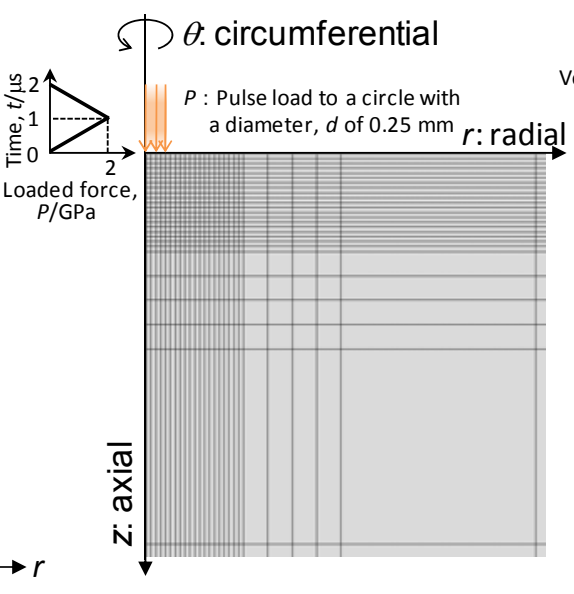

(b) Enlarged area of impact point for WJP

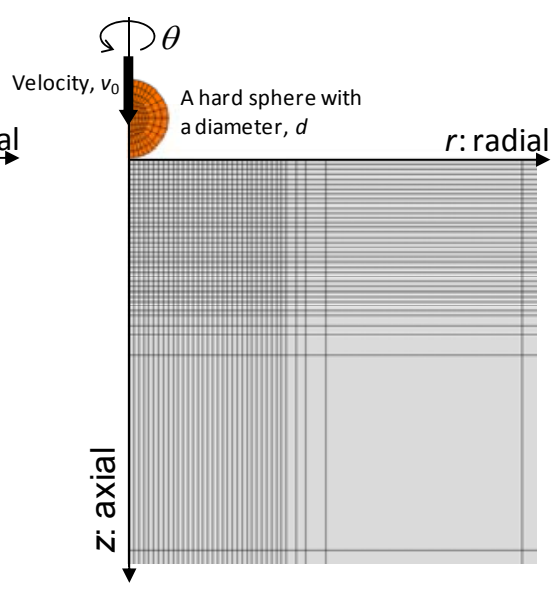

(c) Enlarged area of impact point for SP

Fig. 2 Mesh configuration and pulse-load using WJP for elasto-plastic calculations. 
Table 2 Parameters of austenitic stainless steels for elasto-plastic calculation.

\begin{tabular}{l|c}
\hline \hline Parameters & Values \\
\hline Young's modulus $E$ & $195 \mathrm{GPa}$ \\
\hline Yield stress $\sigma_{\mathrm{y}}$ & $600 \mathrm{MPa}, 1300 \mathrm{MPa}$ \\
\hline Work hardening rate $d \sigma / d \varepsilon$ & $E / 100$ \\
\hline Subsequent yield condition & Isotropic hardening rule \\
\hline
\end{tabular}

Table 3 Parameters of elasto-plastic calculation for SP (density, $\rho: 8.0 \times 10^{3} \mathrm{~kg} / \mathrm{m}^{3}$ ).

\begin{tabular}{c|c|c}
\hline \hline $\begin{array}{c}\text { Diameter of shot } \\
d(\mathrm{~mm})\end{array}$ & $\begin{array}{c}\text { Velocity of shot } \\
v_{0}(\mathrm{~m} / \mathrm{s})\end{array}$ & $\begin{array}{c}\text { Kinetic energy } \\
\pi d^{3} \rho v_{0}^{2} / 6(\mathrm{~J})\end{array}$ \\
\hline 0.4 & 75 & $7.5 \times 10^{-4}$ \\
\hline 1.0 & 19 & $7.5 \times 10^{-4}$ \\
\hline 2.0 & 6.7 & $7.5 \times 10^{-4}$ \\
\hline 3.0 & 3.7 & $7.5 \times 10^{-4}$ \\
\hline
\end{tabular}

\section{Results}

\subsection{Plastic strain of surfaces processed using peening}

The depth profiles of the cross-sectional hardness (tested at a force of $0.049 \mathrm{~N}$ ) of the initial surface, surface processed using WJP, and surface processed using SP are shown in Fig. 3(a) (Kaneda, et al., 2009). The initial surface showed a homogeneous hardness distribution of $159 \pm 9 \mathrm{HV}$ at depths from 20 to $400 \mu \mathrm{m}$. On the other hand, an increase in hardness was observed near the processed surfaces. The surface processed using WJP showed an average hardness of $217 \mathrm{HV}$ at a depth of $20 \mu \mathrm{m}$ and an increase in hardness at depths up to $80 \mu \mathrm{m}$. The surface processed using SP showed an average hardness of $406 \mathrm{HV}$ at a depth of $20 \mu \mathrm{m}$ and an increase in hardness at depths up to 180 $\mu \mathrm{m}$. Thus, the surface processed using WJP showed less increase in hardness and a shallower hardened layer than that using SP. Compared to the relationship between hardness and corresponding plastic strain calculated using Eq. (1) in Fig. 3, the plastic strain at a depth of $20 \mu \mathrm{m}$ corresponded to about 0.16 for the surface processed using WJP and larger than 0.916 for the surface processed using SP.

The average GROD in an area of $300 \times 10 \mu \mathrm{m}^{2}$ was calculated for every $10 \mu \mathrm{m}$ of depth. The average GROD depth profiles are shown in Fig. 4(a) (Ishibashi, et al., 2010). The GROD in the map of the initial surface was less than 1 degree. Both processed surfaces showed an increase in GROD from the surface edge to about $300 \mu \mathrm{m}$ in depth. The GROD near the surface processed using SP was much larger than that near the surface processed using WJP. Notably, an EBSD unmeasurable area existed near the surface processed using SP because of the large deformation. Thus, the surface processed using WJP was deformed as deep as that using SP but deformed much less. The depth profiles of the corresponding plastic strain calculated using Eq. (2) from the average GROD depth profiles in Fig. 4(a) are also shown in Fig. 4(b). The corresponding plastic strain from the average GROD in Fig. 4(b) was lower than that from the hardness in Fig. 3(b). This reveals that a surface using peening shows different deformation of grains from the bulk by tension in which base data were taken for the relationship between strain and average GROD. 


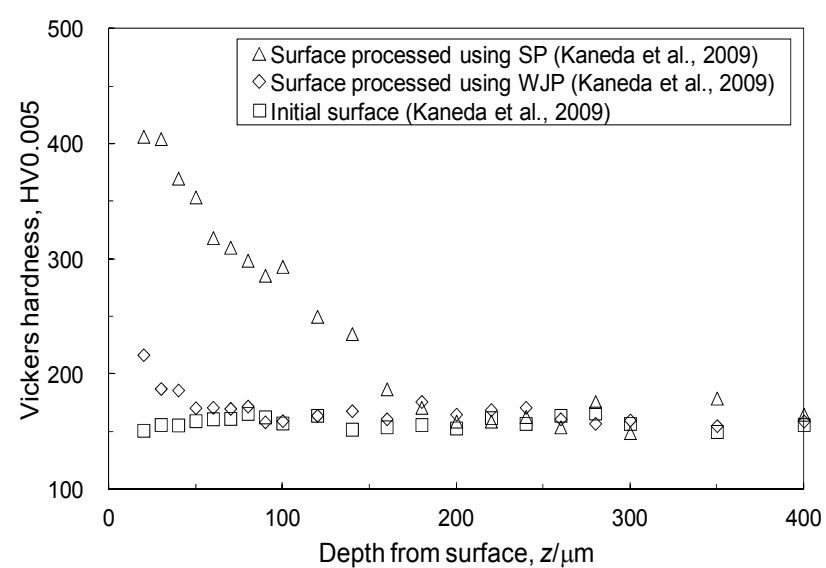

(a) Measurement results

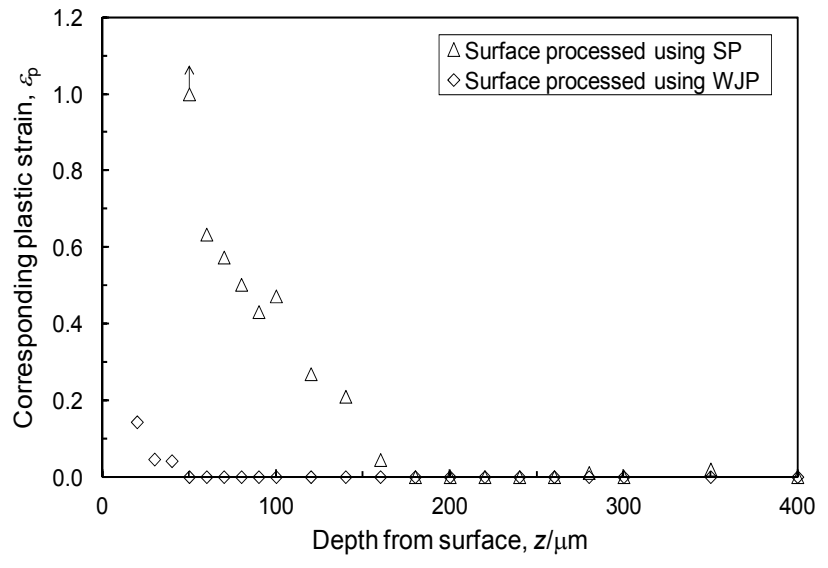

(b) Corresponding plastic strain

Fig. 3 Cross sectional depth distribution of Vickers hardness and corresponding plastic strain from Vickers hardness in surfaces processed using SP and WJP.

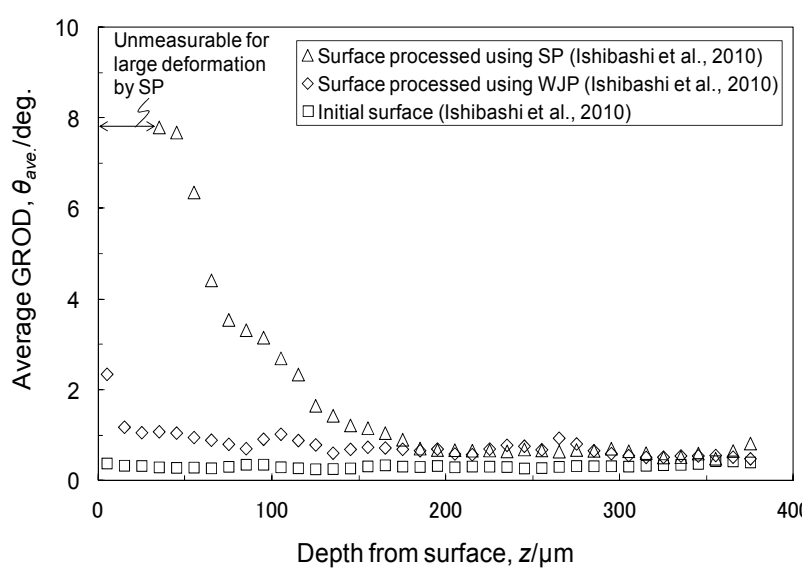

(a) Measurement results

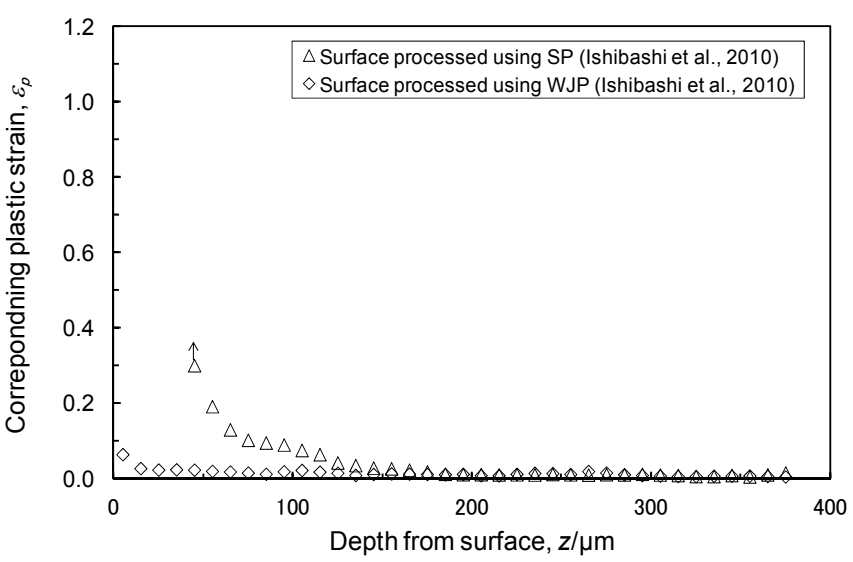

(b) Corresponding plastic strain

Fig. 4 Cross sectional depth distribution of average GROD and corresponding plastic strain from average GROD in surfaces processed using SP and WJP.

\subsection{Elasto-plastic calculation}

\subsubsection{Surface processed using WJP}

The calculated stress-strain history during three shock wave impacts and the cross-sectional residual stress distributions from the three impacts using WJP for the steel specimen with $\sigma_{\mathrm{y}}$ of $600 \mathrm{MPa}$ are shown in Fig. 5. The shock wave impacts by using WJP generated compressive stress with positive strain in the radial and circumferential directions and with negative strain in the axial direction, as shown in Fig. 5(a). The depth profiles of the radial residual stress in Fig. 5(b) indicate that compressive stress exists up to a depth of approximately $300 \mu \mathrm{m}$. The cause of compressive stress is discussed in a previous paper (Ishibashi, et al., 2010). A region with radial, circumferential, and axial compressive residual stresses exists at the directly processed surface portion. Tensile residual stress is shown at a deeper region for radial residual stress and at an area around the region with compressive residual stress for circumferential and axial residual stresses. The directly processed surface portion expanded against the surrounding restraint during the process and subsequently compressed from the surrounding restraint after being unloaded.

The profiles were calculated under conditions of three impacts; subsequently the upper layer was removed to simulate actual X-ray powder diffraction (XRD) residual stress measurements. The compressive stress near the point of impact decreased due to redistribution after the upper layer was removed. The depth profiles of the radial residual stress 
after removal of the upper layer almost corresponded to that from the XRD residual stress measurement, as shown in Fig. 5(b).

There was almost no additive strain in all directions from the second and third shock wave impacts, as shown in Fig. 5(a). Thus, the stain was saturated in the case of the same loaded force. This is likely the reason the calculated depth profiles of the radial residual stress for the steel specimen with $\sigma_{\mathrm{y}}$ of $600 \mathrm{MPa}$ almost corresponded to that from the XRD residual stress measurement for the steel specimen with $\sigma_{0.2}$ of $260 \mathrm{MPa}$.

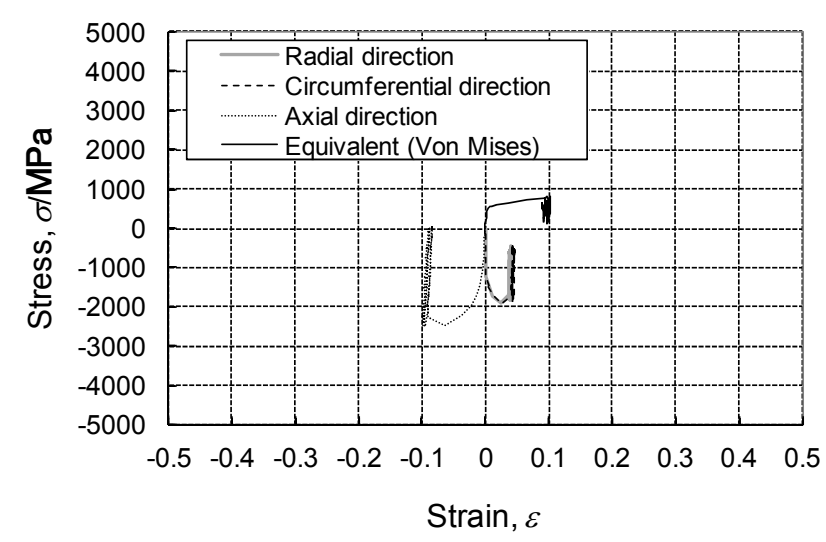

(a) Stress-strain history

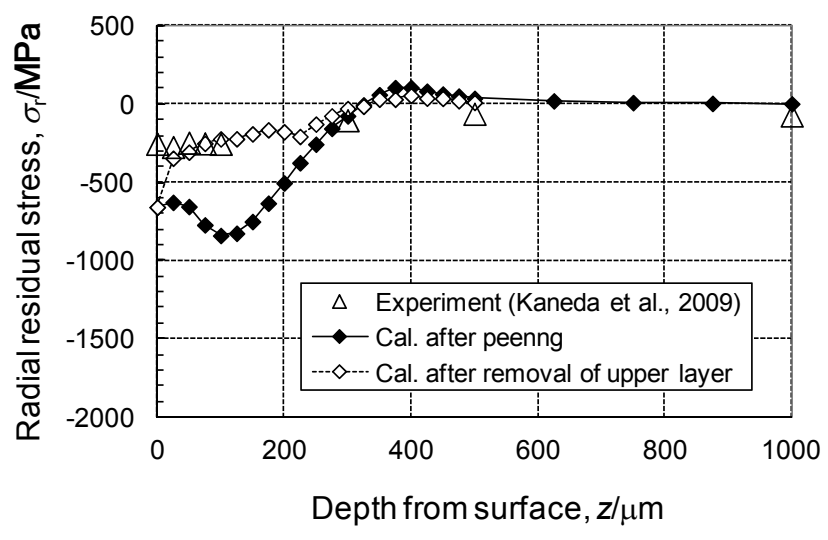

(b) Depth profiles of radial residual stress

Fig. 5 Calculated stress-strain history during three impacts and depth profiles of radial residual stress after impacts for surface processed using WJP. Stress-strain histories of radial direction and circumferential direction nearly overlap.

\subsubsection{Surface processed using SP}

The calculated stress-strain history during three shot impacts and the cross-sectional residual stress distributions from the impacts using SP (shot diameter: $0.4 \mathrm{~mm}$ ) for the steel specimen with $\sigma_{\mathrm{y}}$ of $600 \mathrm{MPa}$ are shown in Fig. 6 . The shot impacts by using SP generated compressive stress with positive strain in the radial and circumferential directions and with negative strain in the axial direction, as shown in Fig. 6(a). The depth profiles of the radial residual stress in Fig. 6(b) indicate that compressive stress exists up to a depth of approximately $380 \mu \mathrm{m}$. The cause of the compressive stress is the same as that using WJP (Ishibashi, et al., 2010).

The additive strain in all directions from the second and third shot impacts was much larger than that using WJP, as shown in Fig. 6(a). Thus, the stain increased by repeated shot impacts. The equivalent stress reached approximately $1300 \mathrm{MPa}$. The calculated stress-strain history during three shot impacts and the cross-sectional residual stress distributions from the impacts using SP (shot diameter: $0.4 \mathrm{~mm}$ ) for the steel specimen with $\sigma_{\mathrm{y}}$ of $1300 \mathrm{MPa}$ are shown in Fig. 7. The steel specimen with $\sigma_{\mathrm{y}}$ of $1300 \mathrm{MPa}$ indicated higher residual stress, but less additive strain in all directions from the second and third shot impacts compared to the steel specimen with $\sigma_{\mathrm{y}}$ of $600 \mathrm{MPa}$, as shown in Fig. $7(\mathrm{a})$.

The calculated depth profiles of the residual stress were compared to that from the XRD residual stress measurement. The depth profile of the radial residual stress after removal of the upper layer for the steel specimen with $\sigma_{\mathrm{y}}$ of $600 \mathrm{MPa}$ almost corresponded to the experimental depth profile, as shown in Fig. 6(b). On the other hand, the depth profile of the radial residual stress after removal of the upper layer for the steel specimen with $\sigma_{\mathrm{y}}$ of $1300 \mathrm{MPa}$ corresponded little to the experimental depth profile, as shown in Fig. 7(b). This likely indicates that the calculated surface for the steel specimen with $\sigma_{\mathrm{y}}$ of $600 \mathrm{MPa}$ has a strain condition similar to the surface processed using SP for the steel specimen with $\sigma_{0.2}$ of $260 \mathrm{MPa}$.

The calculated stress-strain histories during three impacts for the surface ( $\sigma_{\mathrm{y}}$ : $600 \mathrm{MPa}$ ) processed using SP (shot diameter: 1.0, 2.0, and $3.0 \mathrm{~mm}$ ) are shown in Figs. 8(a), (b), and (c). Compared to the calculated stress-strain history by using SP (shot diameter: $0.4 \mathrm{~mm}$ ) shown in Fig. 6, strains from shot impacts decreased as the shot diameter increased. The calculated depth profiles of the radial residual stress after three impacts for the surface ( $\sigma_{\mathrm{y}}: 600 \mathrm{MPa}$.) processed using SP with various shot diameters are shown in Fig. 8(d). As the shot diameter increased, the compressive radial 
residual stress slightly decreased and became slightly deeper. The compressive radial residual stress at the surface particularly decreased close to zero.

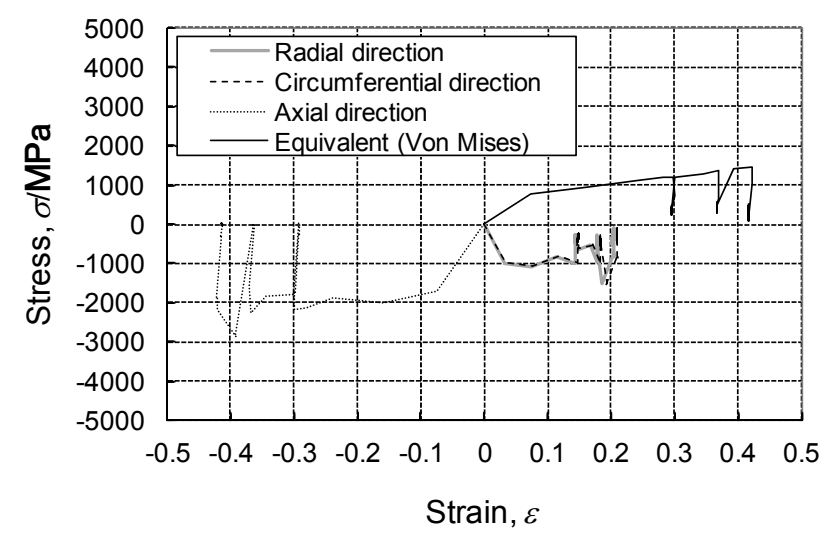

(a) Stress-strain history

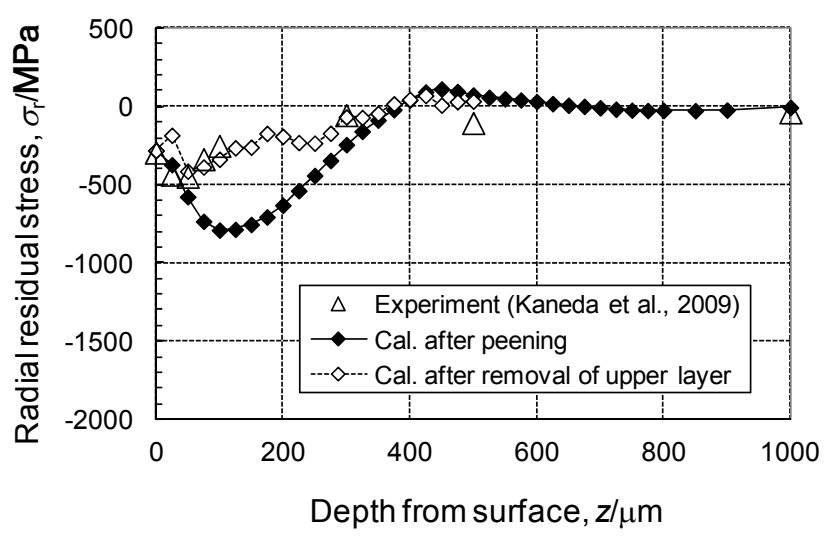

(b) Depth profiles of radial residual stress

Fig. 6 Calculated stress-strain history during three impacts and depth profiles of radial residual stress after three impacts for surface ( $\sigma_{\mathrm{y}}$ : $600 \mathrm{MPa}$ ) processed using SP (shot diameter: $0.4 \mathrm{~mm}$ ). Stress-strain histories of radial direction and circumferential direction nearly overlap.

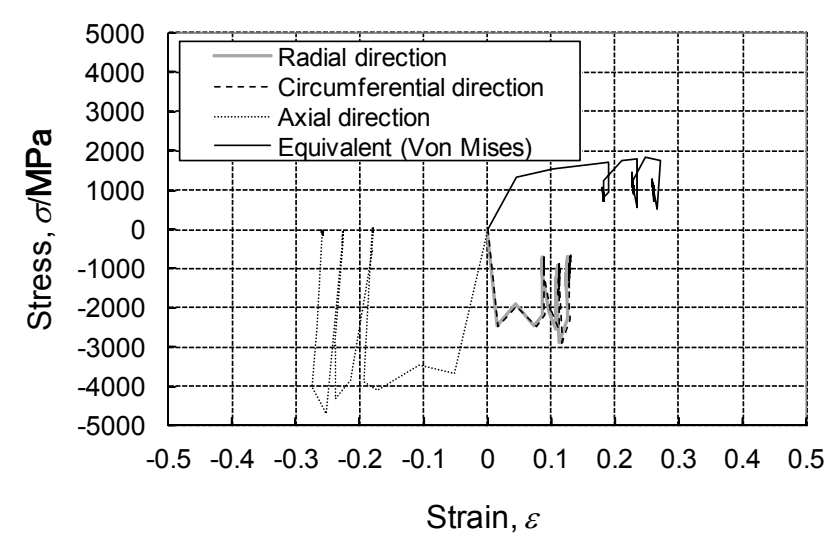

(a) Stress-strain history



(b) Depth profiles of radial residual stress

Fig. 7 Calculated stress-strain history during three impacts and depth profiles of radial residual stress after three impacts for surface ( $\sigma_{\mathrm{y}}: 1300 \mathrm{MPa}$.) processed using SP (shot diameter: $0.4 \mathrm{~mm}$ ). Stress-strain histories of radial direction and circumferential direction nearly overlap. 


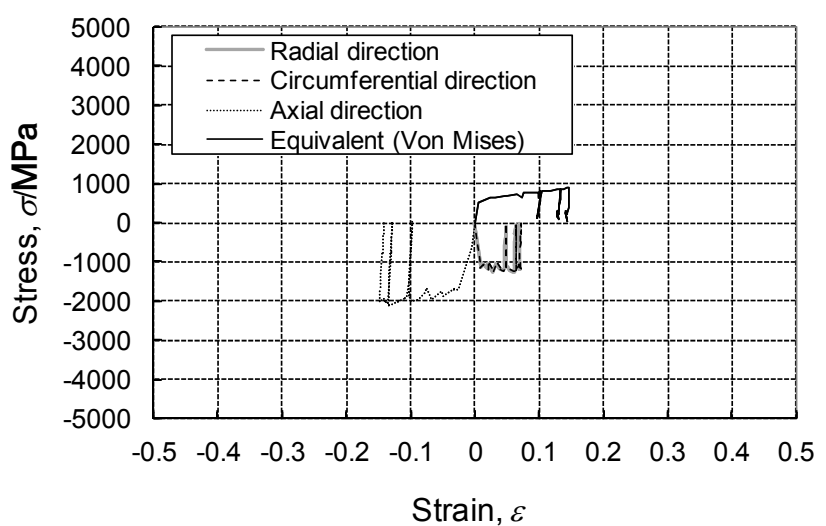

(a) Shot diameter: $1.0 \mathrm{~mm}$

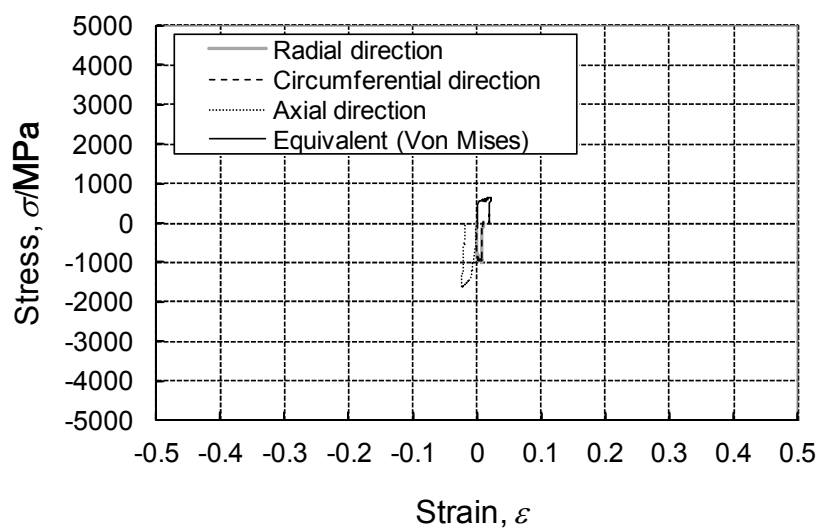

(c) Shot diameter: $3.0 \mathrm{~mm}$

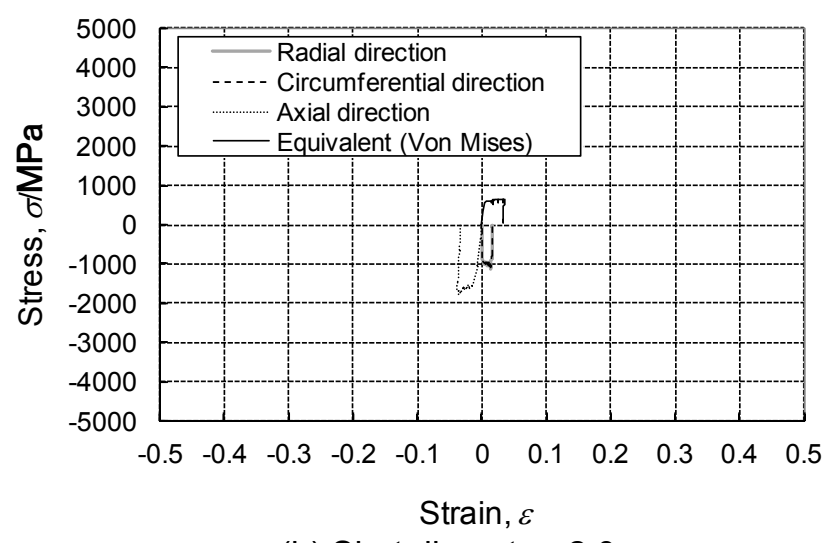

(b) Shot diameter: $2.0 \mathrm{~mm}$

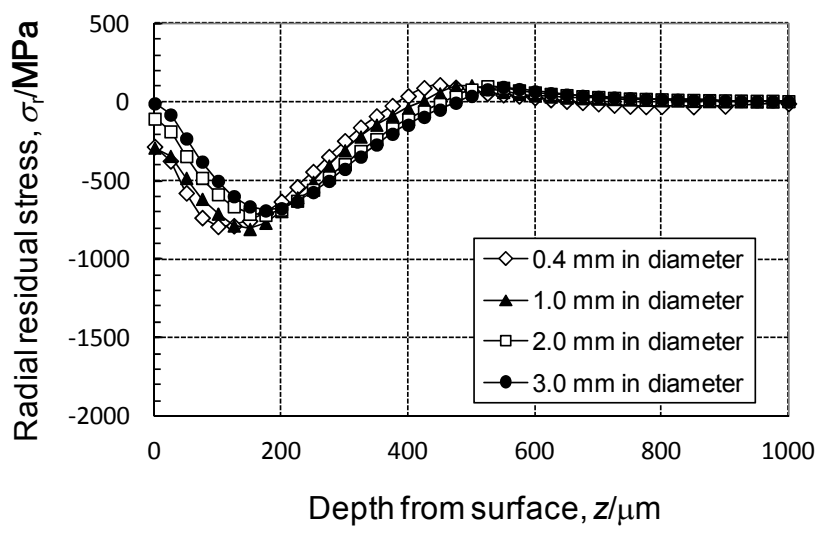

(d) Depth profiles of radial residual stress

Fig. 8 Calculated stress-strain histories during three impacts for surface $\left(\sigma_{\mathrm{y}}\right.$ : $600 \mathrm{MPa}$ ) processed using SP (shot diameter: 1.0, 2.0, and $3.0 \mathrm{~mm}$ ) and dependence of shot diameter on calculated depth profiles of radial residual stress after three impacts. Stress-strain histories of radial direction and circumferential direction nearly overlap.

\section{Discussion}

The SP process resulted in larger deformation at the surface than using WJP. This is considered due to the difference in media impacting the surface. During SP, the shot deforms the surface locally with much higher surface pressure in the early stages of the impact, while during WJP, shock waves deform the surface evenly throughout the wave passage across the surface. Calculated time variations of the Von Mises stress and strain at the center of the loaded area during impact are shown in Fig. 9. The red arrows in Figs 9 (a) and (b) show the times of 0.1, 0.5 and 1.0 $\mu$ s corresponding to Fig. 9(c). The center of the loaded area during SP exhibited higher stress and larger strain than the center during WJP, as shown in Fig. 9(c). From these analyzed results, it can be inferred that the media impacting the surface create a difference in the hardness and microstructure of the processed surface.

An increase in stress concentration leads to larger deformation of the surface according to the above discussion, so SP with large-diameter shots is expected to suppress the stress concentration. The diameter of the loaded area, $d_{1}$ is the maximum diameter of the surface area impacted by a shot, as shown in Fig. 10, and is defined as an index of stress concentration. The characteristic variations of the evaluated positions from the three impacts by shots with various diameters are shown in Fig. 11. The arrows show the imaginary transition of strain and residual stress with work-hardening progression during SP process (shot diameter: $0.4 \mathrm{~mm}$ ). A shot with a larger diameter shows a larger diameter of loaded area. Thus, SP with large-diameter shots suppresses the stress concentration under the same kinetic energy condition. As the shot diameter increased, the equivalent plastic strain decreased and was occasionally less than that using WJP. Moreover, the depth with compressive stress tended to increase. On the other hand, compressive residual stress at the surface decreased and occasionally became almost zero. Thus, compressive residual stress introduction with lower plastic strain processed using SP is considered achievable by using shots with a large diameter and choosing the appropriate peening condition. 


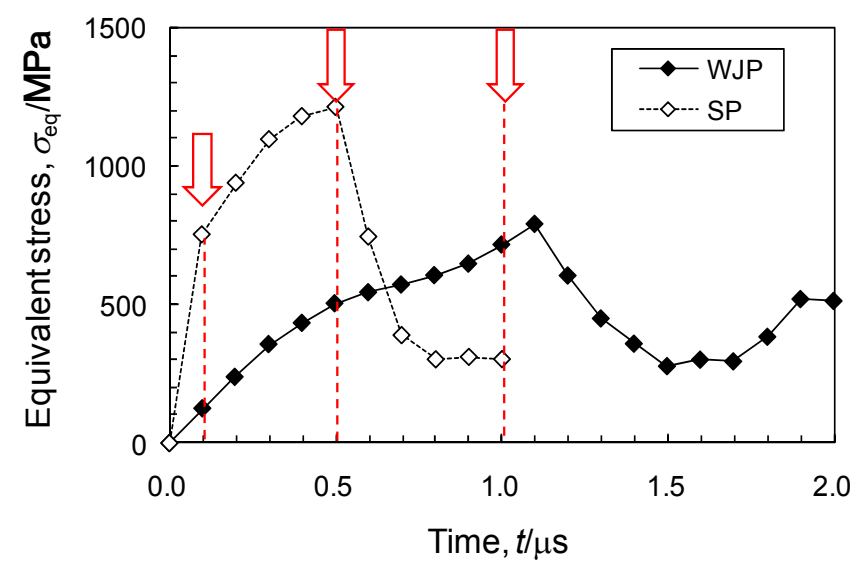

(a) Equivalent stress

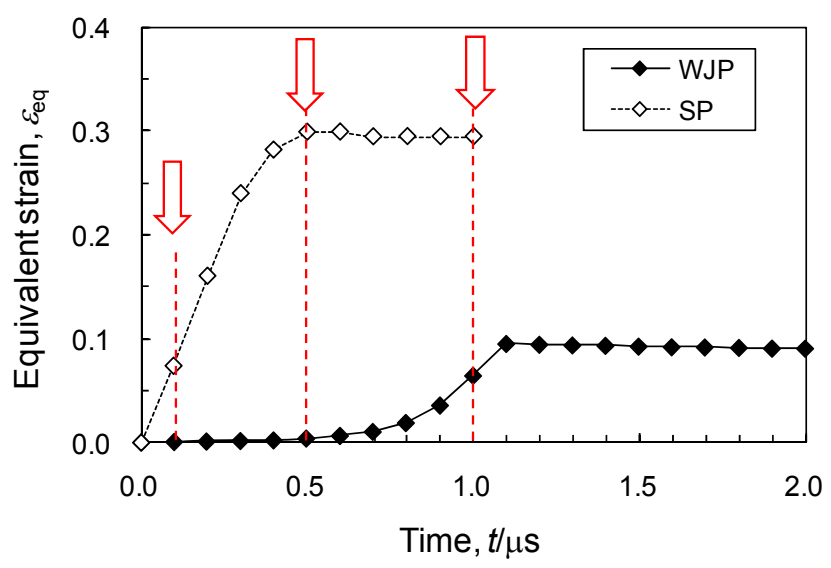

(b) Equivalent strain (Von Mises)


(c) Cross-sectional distribution of equivalent strain (Von Mises)

Fig. 9 Calculated time variation of equivalent stress and strain (Von Mises) at center of loaded area during impact.

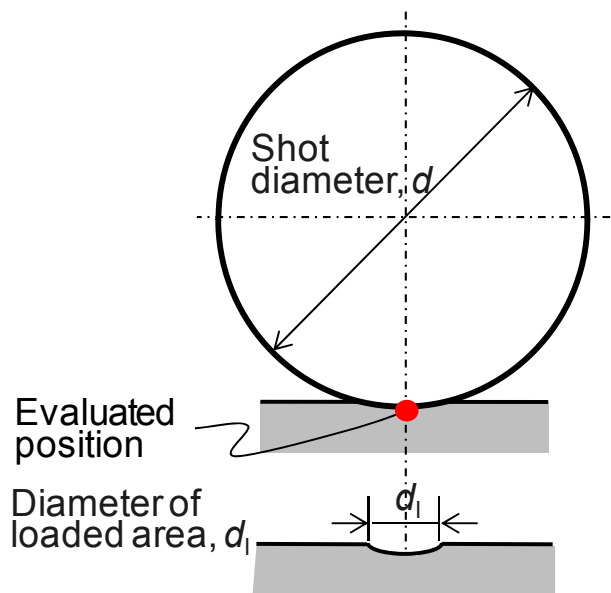

Fig. 10 Evaluated position and loaded area in this analysis. 

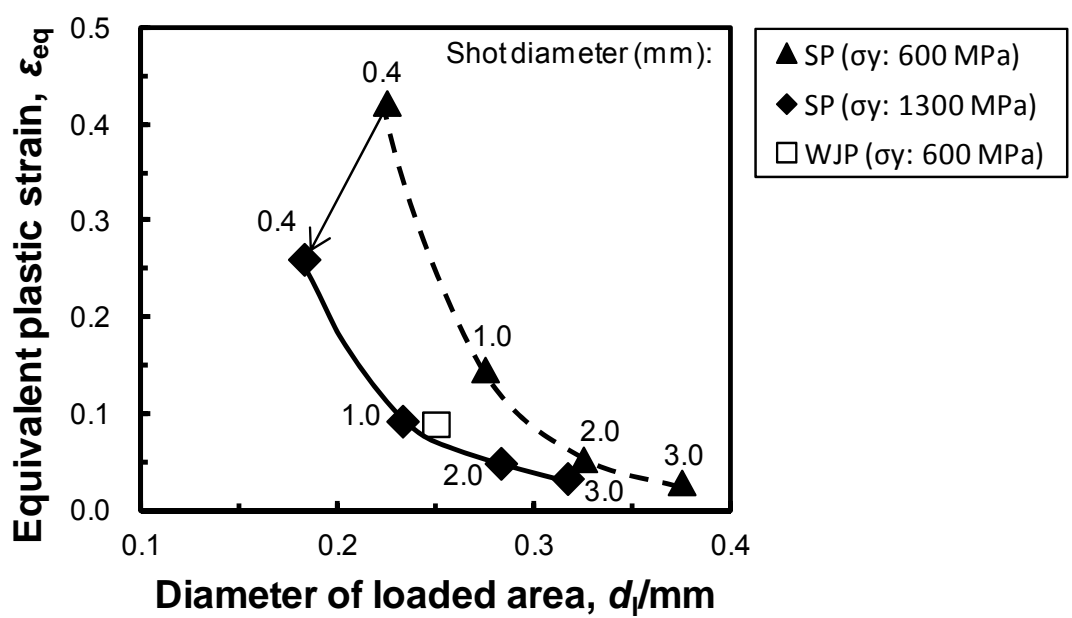

(a) Equivalent plastic strain

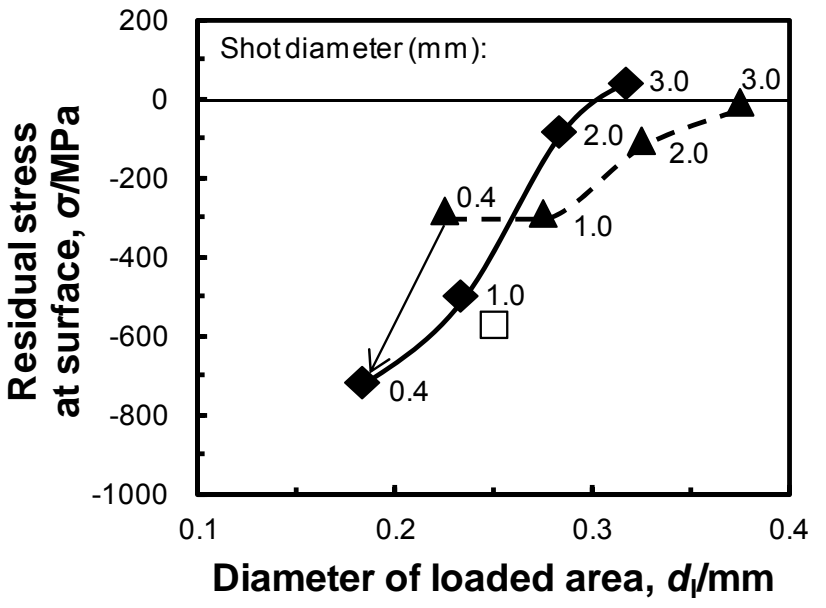

(b) Residual stress at surface

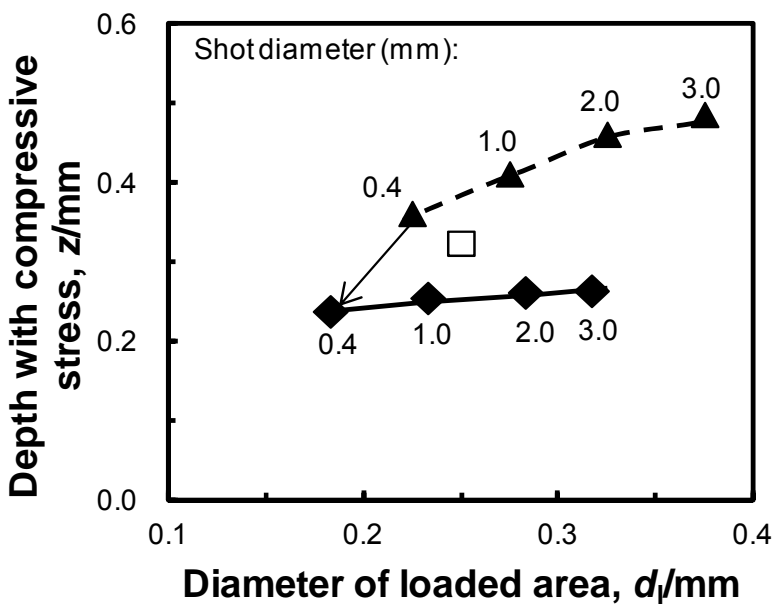

(c) Depth with compressive stress

Fig. 11 Characteristic variations of evaluated positions of three impacts using SP with shots of various diameters.

\section{Conclusions}

Our goal was to understand the cause of the differences in surface properties between surfaces processed using WJP and SP and to examine the compressive residual stress introduction process with low plastic strain using SP. We analyzed the dynamic behaviors of stress and strain in the surface during these processes through elasto-plastic calculations using a finite-element method program and compared the calculated results with measured results obtained through experiments. The following conclusions were reached.

Media impacting the surface create a difference in the hardness and microstructure of the processed surface. During SP, the shot deforms the surface locally with stress concentrating in the early stages of the impact, while shock waves deform the surface evenly throughout the wave passage across the surface during WJP.

A shot with a larger diameter creates a larger impact area on the surface. Thus, SP with a large-diameter shots suppresses the stress concentration under the same kinetic energy condition. As the shot diameter increases, the equivalent plastic strain decreases. On the other hand, the shot is subject to size restriction since the calculated results indicated the compressive residual stress at the surface decreased and became occasionally almost zero as the shot diameter increased. Thus, compressive residual stress introduction with lower plastic strain by using SP is considered achievable by using shots with a large diameter and choosing the appropriate peening conditions.

\section{Acknowledgements}

We would like to express our thanks to Professor M. Mochizuki, Osaka University, who gave us valuable advice. We are grateful to Y. Toyama, Hitachi Power Solutions Co., Ltd. for assistance with elasto-plastic calculation. 


\section{References}

Angeliu, T. M., Andresen, P. L., Hall, E., Sutliff, J. A., Sitzman S., and Horn, R. M., Intergranular stress corrosion cracking of unsensitized stainless steels in BWR environments, Proceedings of $9^{\text {th }}$ International Conference on Environmental Degradation of Materials in Nuclear Power Systems - Water Reactors, TMS, (1999), pp. 311-317.

Fujikawa, S. and Akamatsu, T., The dynamic behaviours of cavitation babbles and the impulsive pressures, Transactions of the Japan Society of Mechanical Engineers. B, Vol. 50, No. 450, (1984), pp. $293-299$ (in Japanese).

Hirayama, H., Otake, A., and Tsukamoto, M., Effect of strain-rate on mechanical properties of carbon steel (JIS SM50) and strainless steel (JIS SUS304), Summaries of technical papers of Annual Meeting Architectural Institute of Japan. Structures II, (1989), pp.1077-1078 (in Japanese).

Ishibashi, R., Hato, H., and Yoshikubo, F., Mechanism of compressive residual stress introduction on surfaces of metal materials by water-jet peening, Proceedings of ASME 2010 Pressure Vessels and Piping Division/K-PVP Conference, Paper No. PVP2010-25175 (2010), pp. 801-813.

Kamaya, M., Wilkinson, A. J., and Titchmarsh J. M., Quantification of plastic strain of stainless steel and nickel alloy by electron backscatter diffraction, Acta Materialia, Vol. 54, No. 2, (2006), pp. 539-548.

Kaneda, J., Tamako, H., Ishibashi, R., Hato, H., Miyagawa, M., and Yamashita, N., Effects of surface treatments on microstructure, hardness and residual stress in Type $316 \mathrm{~L}$ stainless steel, Proceedings of $14^{\text {th }}$ International Symposium Environmental Degradation of Materials in Nuclear Power Systems - Water Reactors, Virginia Beach, Virginia, USA, Aug. 23-27, American Nuclear Society, Inc., (2009), pp.791-802.

Kimura, H., Wang, Y., Akiba Y., and Tanaka, K., Misorientation analysis of plastic deformation of austenitic stainless steel by EBSD and X-ray diffraction methods, Transactions of the Japan Society of Mechanical Engineers. A, Vol. 71, No. 712, (2005), pp. 1722-1728.

Konishi, H., Murakami, Y., Kobayashi, M., and Matsui, T., Mechanism of Creation of Compressive Residual Stress by Shot Peening and Its Effect on Fatigue Strength:Analysis of Residual Stress Produced by a Single Shot, Transactions of the Japan Society of Mechanical Engineers. A, Vol. 66, No. 10, (2000), pp. 1847-1854 (in Japanese).

Kuniya, J., Kasahara, S., Anzai H., and Fujimori, H., Stress corrosion cracking susceptibility of various solution annealed austenitic stainless steels in high temperature Water, Zairyo-to-Kankyo, Vol. 56, No. 1, (2007), pp. 22-28 (in Japanese).

McElhaney, K. W., Vlassak J. J., and Nix, W. D., Determination of indenter tip geometry and indentation contact area for depth-sensing indentation experiments, Journal of Materials Research, Vol.13, No.5, (1998), pp.1300-1306.

Nebu, A., Yamada, K., Dozaki, K., Hidaka, A., Uchida, M., and Sone, T., Investigations on strength of piping for non-condensable gas combustion (Part 3: Estimation of fracture strain of steel pipes subjected to hydrogen-oxygen detonation), Transactions of the Japan Society of Mechanical Engineers, Vol.81, No.827, (2015), p.15-00063 (in Japanese).

Nix, W. D., Elastic and plastic properties of thin films on substrates: nanoindentation techniques, Material Science and Engineering: A, Vols. 234-236, (1997), pp. 37-44.

Ogawa, K., Asano, T., Saito, A., Kawamura, K., Ogino M., and Aihara, H., Measurement and analysis of shot velocity in pneumatic shot peening, Transactions of the Japan Society of Mechanical Engineers. C, Vol. 60, No. 3, (1994), pp. 1120-1125 (in Japanese).

Ogawa, K., and Asano, T., Journal of Society of Materials Science, Japan, Theoretical prediction of residual stress induced by shot peening and experimental verification for carburized steel, Vol. 48, No. 12, (1999), pp. 1360-1366 (in Japanese).

Okada T., and Iwai, Y., Cavitation Erosion Resistance of Materials, Journal of the Japan Society Mechanical Engineers, Vol.91, No.831, (1988), pp. 168-173 (in Japanese).

Saito, N., Enomoto, K., Kurosawa, K., Morinaka, R., Hayashi, E., Ishikawa, T., and Yoshimura, T., Development of Water Jet Peening Technique for Reactor Internal Components of Nuclear Power Plant, Journal of jet flow engineering, Vol. 20, No. 1, (2003), pp.4-12 (in Japanese).

Sano, Y., Yoda, M., Mukai, N., Obata, M., Kanno, M., and Shima, S., Residual Stress Improvement Mechanism on Metal Material by Underwater Laser Irradiation, Journal of Atomic Energy Society Japan, Vol. 42, No. 6, (2000), pp. 567-573 (in Japanese). 
Ishibashi, Hato, Yoshikubo and Miyazaki, Mechanical Engineering Journal, Vol.3, No.6 (2016)

Takeda, K., Taniyama, A., Kudo, T., Uchida, H. and Mizuki, J., SCC behavior at hardened surface layer of 316(LC) in water on high temperature, Zairyo-to-Kankyo, Vol. 58, No. 6, (2008), pp. 228-233 (in Japanese). 